\title{
Feminist Legal Theory as Embodied Justice
}

Roxanne Mykitiuk

Osgoode Hall Law School of York University, rmykitiuk@osgoode.yorku.ca

Isabel Karpin

University of Technology, Sydney, Faculty of Law

\section{Source Publication:}

Martha Fineman (ed.) Transcending the Boundaries of Law: Generations of feminism and legal theory. New York: Routledge (2011), 115-130

Follow this and additional works at: https://digitalcommons.osgoode.yorku.ca/scholarly_works

Part of the Feminist, Gender, and Sexuality Studies Commons, and the Public Law and Legal Theory Commons

\section{Repository Citation}

Mykitiuk, Roxanne and Karpin, Isabel, "Feminist Legal Theory as Embodied Justice" (2011). Articles \& Book Chapters. 2713.

https://digitalcommons.osgoode.yorku.ca/scholarly_works/2713

This Book Chapter is brought to you for free and open access by the Faculty Scholarship at Osgoode Digital Commons. It has been accepted for inclusion in Articles \& Book Chapters by an authorized administrator of Osgoode Digital Commons. 


\section{Feminist legal theory as embodied justice}

\section{Isabel Karpin and Roxanne Mykitiuk}

This chapter examines a shift within feminist legal theory from a central concern with sexual difference to one of embodied difference. The subject at the center of this theorizing is marked by bodily (as opposed to sexual) difference from the normative, self-actualizing individual of legal subjecthood. Bioethical and biotechnological inquiries too are concerned with bodily differentiation. Bodies discussed in these contexts are often anomalous or pathologized. They are brought under scrutiny, when they deviate from what is often regarded as "normal," that which is both valorized for its "species typicality" and, by extension, held out as the "natural" state of being (Buchanan et al. 2000).

Our feminist theorizing focuses on the link between biological and legal accounts of the embodied subject to interrogate the way that these meaningmaking discourses reinforce and challenge each other. This approach provides opportunities for rethinking a just response to the existence of non-normatively embodied others. Thus, we examine legal responses to the bodies of nonnormative selves: those classified as "disabled" or otherwise anomalous. While this shift moves away from a specific focus on women's bodies to bodily difference more generally, women's bodies remain central to our analysis because the liberal conception of the subject valorizes bodily states more easily managed by men's bodies. Women, especially through pregnancy, are destined to fail at this marker of autonomy and individuality (Karpin 1994; Mykitiuk 1994). The impetus for our interrogation originates in the work of feminist legal theorists who, along with colleagues in the humanities and social sciences, have sought over the last 25 years to (re)position material embodiment as key to feminist analysis. While difference is not always manifest along gendered lines, feminist legal theory operates as a general jurisprudential matrix within which to understand and analyze a broader ideal of embodied justice.

Here, we map out a legal feminism that invokes a commitment to the multiplicity, indeterminacy, and the contingency of the material self, at the same time as recognizing the reality of bodies and the need to live in them. While accepting instabilities as inevitable, we do not deny that we have bodies, nor do we seek to transcend them. Instead, we argue that law's repertoire of responses should move beyond regularization, normalization, and stabilization. 


\section{Deposing liberal legal feminism}

As part of the deconstruction of liberal feminism, ideals such as independence, autonomy, objectivity, and disembodied abstraction have been radically interrogated (Fineman 2000; Thornton 1999; Williams 1991). For instance, Martha Fineman offers a compelling critique of liberal individualism through her thesis on the inevitability of dependency. Arguing that independence is an imaginary state that fails to account for the myriad ways in which dependency is masked or managed by familial and intimate relationships, she challenges the fundamental claim that independence is a self-evident good toward which we should all strive and around which our legal regimes should be organized. The fact that individuals almost always "exist in family or relational contexts" undermines the primacy of a claim to independence as any kind of ideal state (2000: 14).

Patricia Williams, too, challenges us to recognize our situated and embodied perspective by writing her jurisprudence autobiographically and subjectively. In The Alchemy of Race and Rights (1991: 3) she announces from the outset that "subject position is everything in ... analysis of the law." In doing so, she takes issue with a value system based on an unattainable abstract, the disembodied "neutral" and "objective" individual who is the subject, interpreter and enforcer of law.

Similarly, Margaret Thornton exposes the way that the liberal subject of law is a spectral abstraction denuded of its concrete reality and limitations. In her examination of Australian constitutional law she says:

"constitutionalism" typically involves the treatment of issues at a very high level of abstraction so that distinctive private or subjective features are sloughed off. Thus, issues ostensibly located within the public domain of law can also be hidden from view, if contrary to the interests of benchmark men In this way, the body of an individual complainant can become a mere spectre behind the text.

(Thornton 1999: 754)

The traditional liberal and rationalist conception of the bounded self, identified by a controlling rationality whose integrity must be defended against invasion has thus been the subject of a sustained critique within feminist legal discourse.

The incommensurability of material limitation with the ideology of liberal legalism is an essential and motivating device in our feminist theorizing as well It has led us to focus on the relationship among biomedical discourse, law, and feminist legal theory as fundamental. Our work is in line with what Fletcher et al. (2008: 341) describe as a "shift from more familiar notions of sexual difference to embodied differences."

While engagement with biomedical discourses and health law is a dominant organizing frame for our legal theoretical approach, our work is nevertheless overtly and determinedly within the genre of feminist legal theory. Our critical engagement with the normative legal subject is a feminist engagement regardless of whether the non-normative subject on whose behalf the critique is made is gendered female. We make this appropriative claim for feminist legal theory not because we reject the possibility of critiques of normativity from other quarters indeed we draw heavily on the work of disability studies critiques (Davis 2002; Garland-Thomson 1997; Scully 2008; Thomas 2007), postmodern philosophies (Grosz 1994; Haraway 1991; Shildrick 1997, 2002) and other writings about the body (Bordo 2004; Frank 1995). Rather, our critique of normativity derives from and depends on our feminist legal theoretical foundations and their generational origins. The work of Finenan's feminist legal theory project, to which this book is a tribute, has been instrumental in this regard.

The ontological role of feminist legal theory does not stop when we discuss other kinds of enmbodied lives. Indeed, Shildrick describes the ontological role of feminism in the critique of a modernist discourse that devalues other others apart from women as follows:

Since the beginning of its rejuvenation in the second half of the twentieth century, feminist theory has been marked by the recognition that many of the most fundamental tenets of modernist discourse have supported schemata in which not only women, but other others, have been systematically devalued. In response, feminism has set up alternative models of ontology, epistemology and not least ethics, which challenge both the discursive primacy of the universal, white, able-bodied, masculinist subject and the normative codes by which that subject is supposed to live.

(Shildrick 2005a: 15)

She goes onto say that the attention to context and specificity that feminist scholarship offers is "a powerful challenge to what counts as the legitimate ground for bioethical inquiry" (2005a: 16). We argue that such a feminist sensibility equips us to engage in a thoroughgoing legal critique of normativity more generally and normative embodiment specifically.

\section{Embodying justice}

Our approach to embodiment wrestles with the notion that bodies have a material reality - our skin, blood, ligaments, and DNA do exist. However, "the meanings of the body are facts of culture-meanings that are provisional, multiple and ambiguous, shifting from context to context" (Sclater 2002: 5). Embodiment is a construct of shared understandings, made real by scientific/ biomedical, cultural, and legal accounts, among others. Biological accounts do not simply offer up a description of what is natural. As Sclater (2002: 5) argues, while "the body ... appears as a 'natural' entity that seems to stand outside of history, society and culture," what we see reflected in the discourse of nature 
or "the natural," are actually "cultural concerns embedded in the language of science; science working to negotiate the boundaries of culture."

It is necessary to unpack the unstated assumptions about the meanings (both natural and cultural) attributed to different forms of embodiment and normative embodiment in particular, in both the legal and biomedical contexts and where the two cross paths. Here, we interrogate the concepts of normal and disabled, healthy and diseased, and able-bodied and impaired. We challenge the idea of a "normal," "natural," or "pre-cultural" body as a benchmark against which other bodies are judged. "We track the way in which bodies (within medico-legal and biotechnological discourses) are regulated and managed in relation to shifting normative ideals" (Karpin and Mykitiuk 2008: 414). While for Sclater (2002: 5) "the body emerges as a contested site," we focus on law's role in adjudicating its meaning.

Before considering non-normative embodiment, we first examine two instances where the female reproductive body has confounded the "naturalization" of legal categories via biological claims. These cases illustrate the foundations of our theory of embodied justice in feminist legal theory that deconstructs the disembodied self as the pre-eminent mode of legal selfhood. We explore the crossover between biotechnological and biomedical accounts of the self and those found in law. While law often relies on biological or biomedical explanations to ground its decisions and definitions, we demonstrate how those decisions and definitions are not biologically determined. Instead, they are thoroughly legal and thus culturally circumscribed.

\section{The filial body}

Law has been instrumental in defining the filial body. As Roxanne (2002: 776) argues, "[ $t$ ] he social recognition of parenthood by law is [generally] understood to follow the biological fact of procreation." Legal relationships of maternity and paternity are granted to those assumed to share an intimate biological relationship with a child based on the understanding of biology's role in the creation of parenthood. This role differs for men and women. However, the development of assisted human reproductive technologies and the consequent fragmentation of the biological and social aspects of procreation expose the social construction of the existing legal paradigm of filiation: every child is biologically related to only two legal parents, one of each sex.

The so-called "natural facts" about a child's legal mother and father actually rely on social and cultural conventions which become reified as "natural" and aligned with the biological. Moreover, wrestling with filiation in the context of reproductive technologies reveals that while "law recognizes that blood can create legal ties ... not all blood relationships are given legal recognition. Law does not always mirror nature and often it is more representative of the "social values' it is employed to protect" (Mykitiuk 2002: 776). In light of the development and uses of assisted reproductive technologies and the multiple parties who may become involved in the reproductive context, "facts of nature" are brought into dispute:

It becomes possible to see how the "naturalness" of heterosexuality and the nuclear family is socially constructed. Not all biological relationships are activated as [legal] ones, and law does not recognize that persons are related to one another through ties of substance and physical bonding even where such ties are not instigated through procreation.

(Mykitiuk 2002: 777-78)

\section{The pregnant body}

Law's use of science to negotiate cultural boundaries in the legal treatment of the pregnant woman is another arena where a culturally circumscribed idea of the "natural" is given articulation and endorsement through legal dicta Significant legislative, judicial, and scholarly energy has been spent debating whether a woman and her fetus should be treated as separate biological entities. If treated as separate the potential for conflict is foregrounded. If the fetus is construed as part of the woman then arguably her rights and autonomy are highlighted. Such a construction leaves the law floundering when faced with a woman who wants to assert the loss of a fetus by third-party negligence or criminal harm as a harm distinct from injury to herself. In these cases, biomedical discourses are utilized to assert a certain view. However, the construction of the fetus as a separate entity from the woman or vice versa relies not on the ascertainment of clear biological facts but on a decision to highlight either fetal differentiation from, or connection to, the woman.

For example courts in the US have been asked to adjudicate whether a woman who takes drugs while pregnant is liable for child endangerment or drug trafficking. These arguments are based on biological processes-namely, that the drugs were delivered to the child via the umbilical cord after it was born but before the cord was cut. Thus, the claim satisfies the legal requirement of biological separation at the same time as insisting on biological connection (Karpin 1994). In the Canadian abortion law case, $R$ v. Morgentaler (1988) we find another example of the flexible use of biological processes in law. Madam Justice Wilson rejected one biological explanation that regards a 24-week-old fetus in utero as human life and possible legal person, in favor of another biological definition, in accord with common law, that only upon live birth does personhood begin (see also Savell 2006, for a comparison with UK and Australia). Similarly in Australia in the NSW case of $R v$. King (2003), a man was convicted of grievous bodily harm to a woman after repeatedly kicking her in the stomach and killing her fetus. At first instance the Crown failed in its argument that the death of the fetus was a form of grievous bodily harm to the mother on the grounds that the fetus was a "unique organism." However, on appeal, Chief Justice Spigelman 
concluded that the fetus is part of the mother and, therefore, she was the subject of grievous bodily harm. Commenting further on the question of the relationship between a woman and her fetus, the Chief Justice disavowed biological certainty, highlighting the contingent nature of that relationship in law:

My review of the authorities indicates that there is no clear rule, applicable in all situations, as to whether the mother and foetus must be considered as one or separate. The answer will turn on the incidents of the particular legal situation under consideration including, where relevant, the scope, purpose and object of a particular statutory scheme.

By setting the frame for determining whether a mother and fetus are separate as dependent on the scope and purpose of the legislation that is providing the relevant remedy, the Chief Justice tacitly acknowledged that the biological is cultural or indeed legal.

In our work on the regulation and prohibition of ex utero embryo research and development for reproductive purposes, we show how shifting definitional points based in claims to biological certainty are used to sideline women from the process of reproductive decision-making. An embryo may be classified as "unsuitable for implantation," in which case the woman will not play a role in determining whether it is implanted (Van Wagner et al. 2008). By contrast, individuality migh be attributed to embryonic entities, if not legal personhood based on the asserted uniqueness of their DNA (Karpin 2006). Indeed amendments to the Australian Prohibition of Human Cloning for Reproduction Act (2002) resulted in redefining an embryo based on a precise understanding of the biological point in time when individuality is manifest. The amendments adopted "an independently developed definition of a human embryo to a slightly later stage in the fertilization process (first cell division)" (Lockhart Committee 2005: xv). First cell division was described "as determinative on the basis that the community consensus is a "new and unique genetic entity is formed' only after the genetic material from the male and female pronuclei combine" (Karpin 2006: 606; Karpin and Ellison 2009). In fact, biologically speaking, the embryo has no capacity for individuality (in its social and cultural sense) without a woman willing to gestate it to live birth

So far we have been using these examples to map out systematically the relationship between law and biological accounts of the self. These examples point to the capacity to deploy so-called "natural facts" to political, cultural, and legal ends. Law uses its own criteria of significance and creates its own truth. I continues to reinforce constructions of natural bodies that are in tandem with other dominant discourses of the body, particularly biomedical discourses. Law has been too ready to defer to scientific and medical expertise about bodies, sometimes opting out of addressing fundamental ethical questions and disenfranchising some citizens. However, law also "undermines its own project by it own location in culture, and by its reification of the body as something needing to be regulated" (Sclater 2002: 5). As Sclater (2002: 5) argues, "discourses and practices designed to civilise, regulate and manage the unruly, unpredictable body proliferate," legislating the body as a contested terrain. At the same time, what science knows about the body is shifting and its truth is provisional. As our major source of information and meaning about the limits of the human being biomedical assumptions about normality affect law and what it says about normality, especially with regard to health care and disability.

\section{Embodying justice through feminism}

The legal subject in its liberal form has specific capacities that law is supposed to facilitate and protect: independence, autonomy, the freedom to make rational choices, and protection against incursion. These capacities do not stand up to feminist scrutiny. Ostensibly they are attached to a body that is held out as normative and around which fundamental values of justice, equality, harm, fault and dignity are constructed and defined. However, this body, which is claimed to be no body in particular is, in fact, a very particular kind of body (Mykitiuk 1994). The liberal subject is still the pre-eminent mode of selfhood in law. But it is no surprise that that liberal subject is attached to a very specific body: that which has accrued sufficient social, economic, cultural, and political resources to minimize the impact of its dependency and interconnection with others. Isabel has argued elsewhere that:

[b]odily transgressions do reside within these individuals, but they are accommodated to a point where they appear value-neutral, enabling the façade of independence to be reified in their favour. Those who demand an autonomy of self that incorporates care, responsibility, connection, dependence and even immersion with the other are seen as a definitional paradox - transgressive, messy mixed-up failures. However, it is this conception of self around which law, social, and biomedical discourses must circulate in order to ensure equality and justice.

(Karpin 2005: 197)

A feminist reconfiguration of all bodies as unbounded, always dependent, and subject to the other would require a complete rethinking of the system of justice because it confounds liberalism's individuated self. This approach calls for a conception of justice based on bodily connection and dependence. Feminist theoretical critiques of liberal subjectivity and their assertion of the inevitability of dependence and vulnerability (Fineman 2000, 2008) offer an alternate way of responding to embodied relationships in the contexts in which we work, namely the crossover between biomedical discourses and law.

Take for example the broad area of the legal regulation of genetics. A feminist legal theory of otherness suggests an alternate way of thinking through the initial liberal anxiety produced by the possibility of the intimate connections and 
interconnections that genetics reveals. Regulating in the area of genetics offers the perfect opportunity to reconstruct the legal self in feminist terms as intimately connected with and susceptible to immersion with others. We might use genetic discourses for instance "to generate anxiety about the stability of liberal identity so that its current beneficiaries find themselves at the margins with the rest of us" (Karpin 2005: 197).

The use of genetic testing has the potential to show that "we are all in some way 'impaired' by highlighting the magnitude of human genetic variation, and by demonstrating that everyone has genetic 'abnormalities" (Taylor and Mykitiuk 2001: 69). Moreover, the use of predictive genetic testing creates a new category of people - the "worried well" or the "not yet sick" (Lippman 2006: 18). The use of genetic technology can have the effect of identifying otherwise well individuals with genetic susceptibilities to particular disease as unhealthy or with suspect health. People who have been tested often live their lives according to strategies of health management and risk minimization to prevent the future development of the predicted disease or condition. In some cases the disease or condition never develops. Individuals, made to feel vulnerable and genetically compromised, do find themselves at the margins with the rest of us. In order to appropriate genetic discourses, however, "[] aw in this new frame must take as its base unit a subject that is inevitably connected, vulnerable and dependent" (Karpin 2005: 197); for, genetics offers us a unique form of individuality that connects us to genetically related others. This form of individuality "disables the liberal individual premised on a distinct and separate selfhood. Instead it enables or renders able-bodied a transgressive individual whose very selfhood is already connected and vulnerable to someone else" (Karpin 2005: 198).

A central concern animating feminist critiques of law is the unsustainability of the disembodied subject of law. Female bodies, embryonic bodies, and normative bodies are given legal definition through the use of biomedical discourses yet, that definition is not fixed in "natural facts." Rather, it is fluid and contingent. In line with the shift from gendered difference to embodied difference, highlighted at the chapter's beginning, we turn to engage broader issues of nonnormative embodiment. We will look at law's regulation of conjoined twins and people with disabilities.

\section{Conjoined embodiment}

Conjoined embodiment challenges deeply rooted, internalized, and naturalized beliefs concerning the corporeal makeup of a human being. In place of a normative autonomous, stable, singular, and detached self for whom the body is often absent, conjoined embodiment (like pregnancy) offers the unsettling prospect of ambiguous and shared bodily boundaries, negotiated selfhood, and the possibility of being together in one. In contrast to the normative liberal subject, conjoined twins offer a further example of the need for embodiment to become an ontological foundation of the self. They suggest the possibility of an attachment to the corporeality of being and a conception of selfhood that is not defined and valued by its distinctiveness from the other.

Conjoined embodiment offers an opportunity to re-craft and rethink both the theoretical premises and assumptions that have been used to legitimate the normative modern subject and to engage the hegemonic imperatives which alienate, oppress, and suffocate non-conforming subject positions. The phenomenon of conjoined embodiment implicates both bodily existences that are not neatly compartmentalizable and resist classification and bodily existences which do not matter, are discounted, or are marginalized

Conjoined twins, like all other "other" bodies, exist as abject and grotesque. They provoke visceral reactions of horror, disgust, sadness, and pity. Moreover, the disciplinary regimes, including biomedicine and law, that reify corporeal boundedness and subjugate non-normative morphologies are exposed and problematized by the conjoined twin. As a medical anomaly, conjoined twins are categorized as a deformity and a birth defect predicated on the normalcy of discreteness of identity. Medical discourses attempt to account for conjointness by positing explanations of where something naturally went wrong, how a "freak" of nature occurred, and how and why the anomalies should be fixed. Biological and medical discourses provide that "siamese twins ... occur ... when $\ldots$ an egg in the womb fails to divide successfully" (Clark and Myser 1998: 4). Conjoined embodiment is represented as a condition in which nature has neglected to finish its prescribed embryological work. Thus the need to "fix" conjoined bodily experiences is built into its very definition. From the outset conjoined twins are conceptually crafted as two individuals fused together whose "humanness" can only be achieved through medical intervention. The embodiment of conjoined twins is "so threatening to the order of things ... that they are almost always surgically normalized" (Garland-Thomson, 2001: 11).

This approach to embodiment and personhood is taken up in legal discourse. A compelling example is the UK case, Re A (Conjoined twins: Medical treatment) (2000). As was the case in $\operatorname{Re} A$, "not infrequently one conjoined twin is 'sacrificed' to save the other from the supposed abnormality of their embodiment" (Garland-Thompson, 2003: 13). These actions are justified as preventing suffering and creating well-adjusted individuals. In Re A, Lord Justice Ward makes general comments about the nature of embodiment and its link to dignity and integrity to justify the separation that will kill one twin. With respect to the twin who will die if surgical separation occurs, he states:

The only gain I can see is that the operation would, if successful, give Mary the bodily integrity and dignity which is the natural order for all of us. But this is a wholly illusory goal because she will be dead before she can enjoy her independence and she will die because, when she is independent, she has no capacity for life ... In terms of her best health interests, there are none. 
Nevertheless, Lord Justice Ward ultimately decides in favor of the surgical separation, arguing that the life of the twin is so compromised by her dependence on the other twin as to be a life destined for death:

In summary, the operation will give Jodie the prospects of a normal expectation of relatively normal life. The operation will shorten Mary's life but she remains doomed for death. Mary has a full claim to the dignity of independence which is her human entitlement. In the words of the Rabbinical scholars involved in the 1977 case in Philadelphia, Mary is "designated for death" because her capacity to live her life is fatally compromised. The prospect of a full life for Jodie is counterbalanced by an acceleration of certain death for Mary. That balance is heavily in Jodie's favour.

The fatal compromise to which Mary must succumb is evinced through her chronic incapacity for independence compared with her sister Jodie who ultimately could live independently. Lord Brooke ends his judgment with a similar response to the horror of dependency: "Finally, the doctrine of the sanctity of life respects the integrity of the human body. The proposed operation would give these children's bodies the integrity which nature denied them" (1052). Integrity, for Mary at least, is only available in death

Re $A$ highlights the difficulty of relying upon an idealized notion of selfhood when analyzing the rights of legal persons. The use of the phrase "the natural order" as a benchmark for determining personhood and integrity stands in stark contrast to the artificial way in which that natural order must be achieved. According to Lord Justice Ward:

The first step is to take the scalpel and cut the skin. If it is theoretically possible to cut precisely down the mid-line separating two individual bodies, that is not surgically feasible. Then the doctors have to ascertain which of the organs belong to each child. That is impossible to do without invading Mary's body in the course of that exploration. There follow further acts of separation culminating in the clamping and then severing of the artery. Whether or not the final step is taken within Jodie's body so that Jodie's aorta and not Mary's aorta is assaulted, it seems to me to be utterly fanciful to classify this invasive treatment as an omission in contra-distinction to an act.

The use of the language "the natural" as some kind of claim to the right and the good is flawed and demonstrates the unstated assumptions and contradictions upon which this kind of judgment is made. In this instance, legal and biomedical discourses join forces to literally carve out the autonomous legal subject. Biomedicine is not just a technology, it is also an interpretive framework that reflects and shapes our attitudes to human diversity, normality, and abnormality. As Rosemarie Garland-Thomson (2002) suggests, in biomedicine there is a pervasive will to normalize the non-standard body. One could argue that these surgical separations benefit not the affected conjoined twins, "but rather they expunge the kinds of corporeal human variations that contradict ideologies the dominant order depends on to anchor truths it insists are unequivocally encoded in bodies" (Garland-Thomson 2002: 12-13). Of course, in Re A Jodie did benefit; she would likely not be alive if her sister had remained attached to her. Yet, in many cases the separation of conjoined twins is not driven by the imminence of death, but by the unquestioned assumption that such anomalous embodiment should be normalized. Referring to the routine consideration of separation of conjoined twins made by doctors and parents at birth, Garland-Thomson (2002: 12) argues, "So intolerable is their insult to dominant ideologies" about who we are and who we are supposed to be "that the testimonies of adults with these forms of embodiment who say they do not want to be separated [are] routinely ignored, in establishing the rational for medical treatment."

Sclater (2002: 6) claims that "[L]aw establishes regulations, institutions, and institutes expectations about what is legitimate, acceptable, natural and normal." It is this "narrative" that "gives law its authority" and the power of law "depends less on its ability to coerce and more on its ability to persuade people that the world it describes is the only available world" (Sclater 2002: 6) As seen in the case of conjoinment, law works together with medicine to literally construct the individualistic liberal citizen. Another instance where Sclater's description seems apt is law's use of biomedical discourse to regulate the production and management of disabled bodies. It is with this in mind that we turn to our final example-disability.

\section{Disability}

Typically regarded as a problem for the state, for communities, for families, and for the individual, disability is not generally understood as a feminist issue. However, the importance of feminist theoretical interrogations for discourses about disability has been highlighted by a number of disability scholars. Jackie Leach Scully states that:

d] isability ethics, like feminist ethics, is a form of ethical analysis consciously and conscientiously attentive to the experience of being/having a "different" embodiment. Where feminist ethics' concern is with the non-normativity introduced by gendered bodies ... disability ethics looks at the embodied effects of impairment.

(Scully 2008: 11)

Bonnie G. Smith (2004: 4) also argues that "the disabled, often are seen as women are-either to be too embodied or too frail and wispy to be a real presence." 
Scully, however, distinguishes between disability as a category of material difference and that of gender:

Disability occupies an anomalous position within the typology of gender, class, ethnicity, sexuality or age, because unlike any of these it is possible for a person to exist outside the category. One can be not disabled in a way that one cannot be not gendered, or not have an age.

(Scully 2008: 34)

This assertion that one can exist outside of the category (of disability) adverts to the myriad ways in which disability is claimed by medical discourse to distin guish the individual from species typicality. In fact, a view of embodiment that foregrounds its vulnerability and susceptibility to non-normative states would position all of us as variously capable and incapable, able and disabled at any given moment.

Adrienne Asch (2004: 16) suggests that we question the distinction between people who have impairments and people who do not and instead consider "which people cannot perform which activities in given environments." As Asch states:

arguably, any person now living could, without any change in his or her physical, cognitive, sensory, and emotional make-up, be considered impaired by the same employer, government service provider, place of public accommodation or educational institution if the individual failed to meet particular standards for acceptance into a program or activity that the organisation had established.

By arguing that we shift our perspective to the capacities of all bodies and their many limits, she suggests reconfiguring our social systems in a way that includes the largest range of individuals. All of us are limited by what our bodies are capable of doing in a particular social, cultural, and environmental context. In this sense the category of "not being able" is one outside of which we cannot, in fact, exist. Grounding our legal system and our cultural and social organizations on the concept of normative ability rather than a range of differing abilities results in an unjust and uncompromising framework. What is able bodied is actually structured by the environment.

Turning to law, Asch analyzes the concerns raised by some scholars with the use of the Americans with Disabilities Act (ADA) (1990) by people who would not normally be considered disabled. She argues that opening up disability to a multitude of forms of bodily impairment and vulnerability is, in fact, a more appropriate and just way to deal with disability. She calls this a "human variation approach to disability" (Asch 2004: 18), which shifts the balance away from a narrow range of required accommodations to a norm of accommodation for broad human variation unless (in the case of the $\mathrm{ADA}$ which deals with employment discrimination) the employer can prove that essential functions cannot be performed.

This approach accords with the feminist ethic of embodied justice which we support. It positions the norm as subject to variation and vulnerable to material limits. However as with conjoinment, disability is typically not seen as difference to be accommodated. Rather it is considered so disruptive of individual and community welfare that it is to be prevented, normalized, eliminated, or cured "Solutions" to the "problem" of disability consistently locate it in the individual, not the environment or cultural constructs in which the individual operates In the process, the disabled body/person appears as aberrant. Approaching disability as located only within the individual body is sustained by shoring up an unexamined conception of normalcy from which the disabled depart. This conception of the "normal" often relies upon biomedical discourses as authoritative about the body. Law is a key discourse that relies on biomedical understandings of bodies to regulate and resolve disputes. Nevertheless, biomedical understandings are not stable, knowable facts of nature but fluid and open to law's interpretive purposes.

O'Connell (2009: 143) argues that "[w] ithin the legal framework, a framework that elevates objectivity over subjectivity and valorizes abstractions such as justice and fairness, anti-discrimination laws occupy an unusual space as they concern themselves with questions of embodiment and materiality in often intimate detail." With this in mind we now look briefly at an Australian antidiscrimination case: Purvis v. New South Wales (2003), where the majority and minority judgments used the same biomedical discourse of disability to arrive at different conclusions about the meaning of disability and the determination of discrimination. In this case a boy with disabilities resulting from an illness was denied the protection of the Australian Disability Discrimination Act (1992) after school expulsion due to behavioral problems that caused him to act violently. In concluding that the school had not discriminated, the court made a decision to cordon the question of the boy's disability from the boy's violent behavior, despite the fact that disability was directly responsible for his behavioral issues. The court then chose to compare his treatment (i.e. expulsion) with a hypothetical "non-disabled child" who behaved in the same way. Belinda Smith describes the court's decision as follows:

the factual question for the Court was: Did the school treat Daniel the same as it would treat a non-disabled student who behaved as Daniel had behaved (i.e. violently and disruptively)? The Court found that the answer was yes-Danicl was treated as he was treated because of the circumstances (i.e. his behaviour) not his disability (which was separated). Thus he wa found to have been treated the same as a non-disabled comparator in these circumstances. This meant that the school had not discriminated against Daniel because of his disability.

(Smith 2007: 16) 
This case was dealing with a very violent boy and a school that had made significant but sometimes flawed attempts to accommodate him. Nevertheless, the majority's decision effectively disengaged the boy's disability from his embodied experience of it. Disability here is taken to a "high level of abstraction" (Thornton 1999: 756) and consequently its embodied effects are dematerialized. O'Connell (2009: 143) describes this as the fragility of anti-discrimination law which itself is vulnerable to the "very qualities that are associated with justice." She notes, "as cases are appealed to higher courts, they are increasingly abstracted and disembodied" (2009: 143)

The dissenting Purvis judgments of McHugh and Kirby challenged the majority's definition of Daniel's disability: "In our opinion, the behavioral manifestation of an underlying disorder or condition is itself a disability ..." (para. 27). Even the majority judgments of Justice Gummow, Justice Hayne and Justice Heydon accepted that Daniel had suffered brain damage that affected his behavior (para. 182). Furthermore, the evidence of a neurologist and a psychologist was cited to explain the condition as including "disinhibited and uninhibited behaviour" (paras. 29, 30, 182). Nevertheless, the majority of the Court decided to make the comparator an apparently non-disabled child with the same behavior. The majority was particularly swayed by the fact that there was a gap in the legislative framework. Because of this gap, had discrimination been found, the school could not have argued the exception of "unjustifiable hardship" because it was available only on admission to school, not in relation to expulsion. The dissenting judges opined that the majority should not have corrected this legislative oversight by deciding the case the way they did (see Smith 2007: 19).

Without describing the legislative framework within which the High Court was operating and the constraints posed by the legislation itself, we see that an embodied approach to justice would have shifted the focus away from the requirement for a "species typical" comparator. Embodied justice would allow a move toward inquiry into how the school could accommodate Daniel, examining the specific environmental and institutional accommodations that would need to be in place. Such an approach would recognize that Daniel's violent behavior was likely an irreducible part of him and that measures would need to be enacted and implemented to include him in the school community (with appropriate protective safeguards).

Yet, we need to be mindful that practices and policies of inclusion often send the message that to be disabled is to have a problem that limits, disrupts, or prevents the individual from participating in normal life. Brian Pronger, for example, argues that:

The ethics of inclusion, which tries to bring otherness into a system while requiring it to manifest itself within the structure of the system, appropriates otherness, making it conform to the system. The ethics of alterity, in contrast, works not by inclusion but by openness-openness to otherness in a way that allows the other to deconstruct the system to call into question the system's limits, particularly in its appropriation of others' otherness.

(2002: 17)

In the case of Purvis, an ethics of alterity, and a notion of justice as embodied, requires us to find a way to welcome Daniel into the school community while modifying that institution, its practices, and the social environment, rather than expelling the non-normative body or "fixing it" to conform to the system.

\section{Conclusion}

In our early work we investigated the way in which women were placed as problematic outsiders. We insisted on bringing women into the picture, bringing them into the body of knowledge that informs and is law, while making knowledge of and in law account for women's embodiment. To this end, we have explored the legal regulation and construction of the body, and most often the gendered body. While a part of this work has focused on the context of the use and regulation of new reproductive and genetic technologies, more recently we have explored variant corporeality in the context of conjoined twins and disability/impairment.

Our work, while aimed at re-imagining the significance of embodiment to and for women and the law, also identifies and explores the uneasy relationship between law and embodiment generally and marginalized embodiment in particular. Law does not sit in isolation but in relation to a diverse range of discourses that make up the body of law. Some of these discourses create the body of and in law, while law too shapes the body. In this sense, the body is in law, while law is also in the body, and both-law and the body-are necessarily bound up with shifting cultural discourses and practices. This matrix of relationships points to the mutually constitutive nature of both "body" and "law."

In her 1991 book, Simians, Cyborgs and Women, Donna Haraway proclaimed that "[l]ife is a window of vulnerability. It seems a mistake to close it. The perfection of the fully defended, "victorious' self is a chilling fantasy ... "(224). Haraway, in writing these words, was working within a framework of the biopolitics of immunity. In biology as in law the self-actualizing fully defended, bounded, and autonomous individual is the central figure around which policy, theory, and institutions are built. Martha Fineman also challenges us to take vulnerability as a central organizing premise and to reconfigure our approach to state responsibility and to individual rights and duties around the framework of the "vulnerable self." She says:

What should be the political and legal implications of the fact that we are born, live, and die within a fragile materiality that renders all of us constantly susceptible to destructive external forces and internal disintegration? Bodily needs and the messy dependency they carry cannot be ignored in 
life, nor should they be absent in our theories about society, politics and law ...

(Fineman 2008: 12)

Our situated, self-conscious, undifferentiated, and embodied selves, and our recognition of other "others," are the keys to understanding how we might begin to frame a justice system that truly is just; one that "does not defer, but engages with, alterity," one that "extends a welcome ... to difference ... [and] comes into play precisely where the conventional juridical and moral discourse reaches its limit" (Shildrick 2005b: 42, footnotes omitted). Our account of embodied difference provides the basis for a form of feminist legal theorizing, which, while not always identifiable in gendered terms, offers us a means to push beyond the "limit." In doing so, we afford an opening whereby law can "extend a welcome" to all kinds of difference, better respond to all forms of injustice, and embrace all embodied and vulnerable selves. 